\title{
Quantum Sized Zinc Oxide Immobilized on Bentonite Clay and Degradation of C.I. Acid Red 35 in Aqueous under Ultraviolet Light
}

\author{
Hang Xu, Dandan Zhang, Airong Xu, Fengmin Wu, and Renqiang Cao \\ Chemical Engineering and Pharmaceutics School, Henan University of Science and Technology, Luoyang 471023, China \\ Correspondence should be addressed to Hang Xu; xhinbj@126.com
}

Received 3 June 2015; Accepted 5 August 2015

Academic Editor: Ahmad Umar

Copyright @ 2015 Hang Xu et al. This is an open access article distributed under the Creative Commons Attribution License, which permits unrestricted use, distribution, and reproduction in any medium, provided the original work is properly cited.

Nano-ZnO supported on bentonite was prepared to form composite photocatalyst by sol-gel method. The photocatalyst was analyzed by X-ray diffraction (XRD), scanning electron microscopy (SEM), and transmission electron microscope (TEM). C.I. Acid Red 35 was used as simulating contaminant to be treated by ultraviolet light synergistic with nano-ZnO/bentonite. The results show that $5.7 \mathrm{~nm} \mathrm{ZnO}$ particle was acquired and uniformly dispersed on the surface of the bentonite at calcination temperature of $200^{\circ} \mathrm{C}$. The removal of C.I. Acid Red 35 could reach $84.9 \%$ after 200 min under optimum $\mathrm{ZnO} /$ bentonite dosage of $0.6 \mathrm{~g} \mathrm{~L}^{-1}$. The $60 \% \mathrm{ZnO}$ content in $\mathrm{ZnO} /$ bentonite composite exhibited a great photocatalytic activity to treat C.I. Acid Red 35 . The photocatalytic process followed pseudo-first-order kinetics and the best apparent rate constant was $0.00927 \mathrm{~min}^{-1}$ with correlation coefficient $\left(R^{2}\right)$ of above 0.98 .

\section{Introduction}

Printing and dyeing process is one of the most important chemical industries and makes human being in a colorful world. However, this industry can produce numerous poisonous and harmful wastewater with high chroma, high salinity, and great chemical oxygen demand. Photocatalytic oxidation technology can effectively remove organic pollutants from water, especially from dyeing wastewater [1-3]. Zinc oxide $(\mathrm{ZnO})$ powder, an n-type semiconductor materials, has acquired much attention in the field of decomposition of various organic pollutants [4] for its wide band gap $\left(E_{g}=3.37 \mathrm{eV}\right)$, high electron-hole binding energy $(60 \mathrm{meV})$, good piezoelectric [5], small particle size (nanolevel), and excellent photocatalytic activity [6]. Khan et al. synthesized $\mathrm{ZnO}$ quantum dots exhibiting a high efficiency in the decomposition of methyl orange under UV irradiation [7]. Ameen et al. employed a simple solution method of direct synthesis of $\mathrm{ZnO}$-flower nanomaterials which showed a very fast degradation of crystal violet dye with $96 \%$ removal under UV irradiation with $80 \mathrm{~min}$ reaction time [8]. In order to improve the photocatalytic efficiency, nanostructure $\mathrm{ZnO}$ was prepared by sol-gel method [9] and presented a high activity because of the quantum size effect.

Although nanolevel $\mathrm{ZnO}$ shows a satisfactory performance for degradation of organic contamination, it is a problem that nanocatalyst is difficult to be separated and recovered from aqueous after photocatalytic reaction, which severely limits the application of this system into water treatment. In order to overcome this shortcoming, nano- $\mathrm{ZnO}$ was loaded on some supporters (clay soil, glass marble, CNT yarn, activated carbon, metal screening, etc.) to avoid the separation and recover nanocatalyst [10-12]. Bentonite, as a carrier, has many advantages, such as low cost [10], great stabilization, big surface area, good adsorption performance, and high ion exchange [13]. If nano- $\mathrm{ZnO}$ is immobilized on bentonite, it will be good for settlement and recovery of catalyst. The supporter, bentonite, can improve dispersion of nano- $\mathrm{ZnO}$ and reduce its dosage. On the other hand, bentonite can increase adsorptive capacity of organic contaminant to improve catalytic rate [14]. There were many literatures that bentonite as an excellent carrier was applied in the field of catalysis. For example, Hamzah et al. [15] used bentonite- $\mathrm{TiO}_{2}$ for hydrogenolysis of glycerol in aqueous 
media. Motshekga et al. [10] used bentonite to improve Ag$\mathrm{ZnO}$ catalytic activity.

In this study, the composite, photocatalyst of nanolevel $\mathrm{ZnO}$ loaded on bentonite (nano- $\mathrm{ZnO} /$ bentonite), was prepared by sol-gel technology. The nano- $\mathrm{ZnO} /$ bentonite was characterized by scanning electron microscopy (SEM), transmission electron microscope (TEM), and X-ray diffraction (XRD). The nano- $\mathrm{ZnO} /$ bentonite was used as photocatalyst to decompose an azo dye, C.I. Acid Red 35, in aqueous.

\section{Experimental}

2.1. Nano-ZnO/Bentonite Preparation. $1.16 \mathrm{~g} \mathrm{LiOH} \cdot \mathrm{H}_{2} \mathrm{O}$ was dissolved in $100 \mathrm{~mL}$ anhydrous ethanol at room temperature. $4.4 \mathrm{~g} \mathrm{Zn}\left(\mathrm{CH}_{3} \mathrm{COO}\right)_{2} \cdot 2 \mathrm{H}_{2} \mathrm{O}$ was dissolved in $100 \mathrm{~mL}$ anhydrous ethanol at $80^{\circ} \mathrm{C}$ in an ultrasonic bath. A certain amount of bentonite was added to $\mathrm{Zn}\left(\mathrm{CH}_{3} \mathrm{COO}\right)_{2}$-ethanol solution to form cloudy solution. The $\mathrm{LiOH}$-ethanol solution was added to the cloudy solution under vigorous stirring at $50^{\circ} \mathrm{C}$ for 60 mins. The reaction mixture became $\mathrm{ZnO}$ sol which was supported on the surface of the bentonite. The mixture was stored below $4^{\circ} \mathrm{C}$ overnight to prevent particles from growing rapidly. The white solid would appear and became white gel after being separated from the liquid above by centrifugal machine. The precursor was acquired by purifying white solid. The precursor was calcined for $4 \mathrm{hrs}$ at certain temperature to form nano- $\mathrm{ZnO} /$ bentonite.

2.2. Characterization. Scanning electron microscopy (SEM) was performed with a JSM-740F operated at $3 \mathrm{kV}$ to examine the surface topography of $\mathrm{ZnO} /$ bentonite. Transmission electron microscope (TEM) was carried out using JEM-2010 (JEOL, Japan), operated at $120 \mathrm{kV}$. The crystal phases of nano$\mathrm{ZnO} /$ bentonite particles were analyzed by X-ray diffraction (XRD) on PaNalytical X-ray diffractometer (X'Pert Pro MPD, Netherlands) using $\mathrm{Cu} \mathrm{K} \alpha$ radiation.

2.3. Photocatalytic Experiment. For photocatalytic activity test, a mixture of $200 \mathrm{~mL}$ C.I. Acid Red 35 aqueous solution with certain concentration of nano- $\mathrm{ZnO} /$ bentonite composite was put in a $250 \mathrm{~mL}$ beaker with magnetic stirring. The information of C.I. Acid Red 35 is shown in Figure 1. The position of ultraviolet light was just above the beaker at $10 \mathrm{~cm}$ above the beaker. The radiation source was a $10 \mathrm{~cm}$ long mercury UV lamp (10 W Guangdong Bright Star) and the wavelength of which radiation source was $245 \mathrm{~nm}$. At a certain reaction interval of $40 \mathrm{~min}$, a sample of $10 \mathrm{~mL}$ was taken out and centrifuged at $12000 \mathrm{rpm}$ to remove catalyst. The dyestuff absorbance of C.I. Acid Red 35 in the sample after centrifuging was analyzed by a UV-2102PC UV-Vis spectrophotometer (UNICO, China). The maximum absorption of C.I. Acid Red 35 in UV-visible spectrum is $523 \mathrm{~nm}$. The relationship between absorbance $(A)$ and concentration of C.I. Acid Red $35(C)$ is $A=0.03438 C$ and the correlation coefficient $\left(R^{2}\right)$ is 0.9999 . The removal of C.I. Acid Red 35 is calculated by the following equation:

$$
\text { Removal }=\frac{\left(C_{0}-C_{t}\right)}{C_{0}} \times 100 \% .
$$

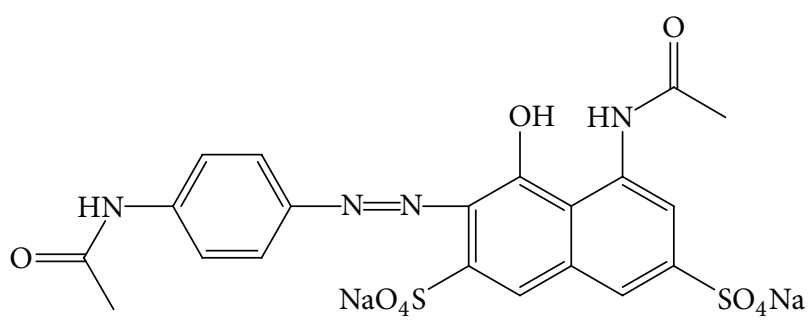

Structure

Molecular formula $\mathrm{C}_{20} \mathrm{H}_{16} \mathrm{~N}_{4} \mathrm{O}_{9} \mathrm{~S}_{2} \mathrm{Na}_{2}$

Molecular weight $566.47 \mathrm{~g} / \mathrm{mol}$

Other names $\quad$ Acid Red 6B; Rose 6B; C.I.18055; Amido Red 6B; and others

CAS number $\quad$ 4321-69-1

FIgURE 1: Structure and characteristics of C.I. Acid Red 35.

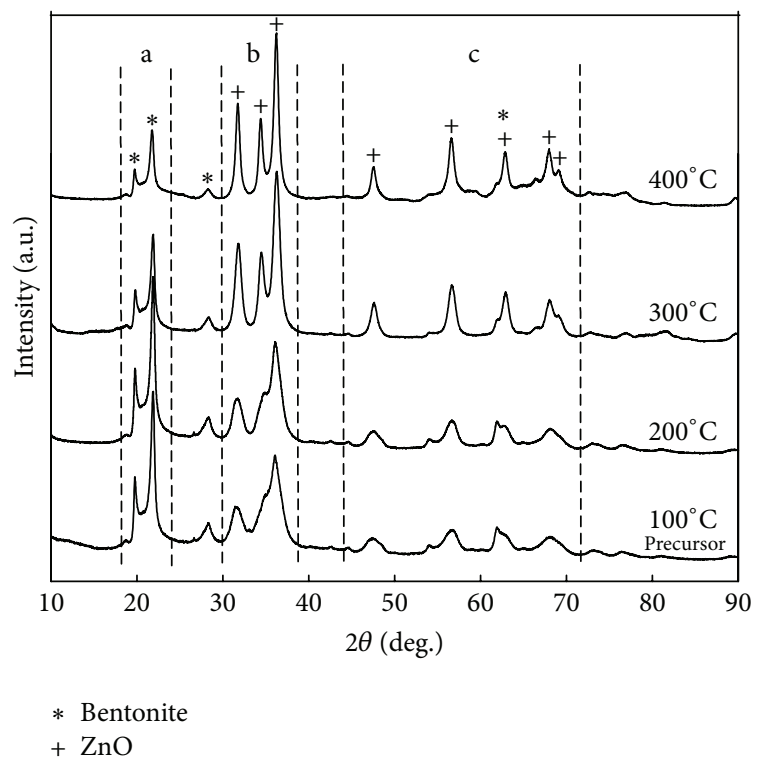

FIGURE 2: XRD of nano-ZnO/bentonite ( $\mathrm{ZnO}$ content: $60 \%)$ at different calcination temperatures.

$C_{t}$ is the concentration of C.I. Acid Red 35 at $t$ time; $C_{0}$ is the initial concentration of C.I. Acid Red 35.

\section{Results and Discussion}

3.1. XRD Analysis. Figure 2 shows the $\mathrm{X}$-ray diffraction patterns of nano- $\mathrm{ZnO} /$ bentonite composite at different calcination temperatures from 100 to $400^{\circ} \mathrm{C}$. Bentonite characteristic peaks are shown at $2 \theta$ values of $18.9,21.9$, and $28.9^{\circ}$ in Figure 2. The peaks of bentonite are evident in all patterns which is also consistent with other reported works $[10,14,16]$. The $\mathrm{ZnO}$ characteristic peaks are shown at $2 \theta$ values of 31.7, 34.4, 36.2, $47.5,56.5,62.8,67.9$, and $68.8^{\circ}$ in Figure 2 . All peaks can be well indexed to standard patterns (JCPDS 36-1451) without any impurity phases $[5,9,17]$. The major peaks of $\mathrm{ZnO}$ at $2 \theta$ values of $31.7,34.4,36.2$, and $47.5^{\circ}$ can be indexed to (100), (002), (101), and (102) crystal planes [18]. From Figure 2, it 


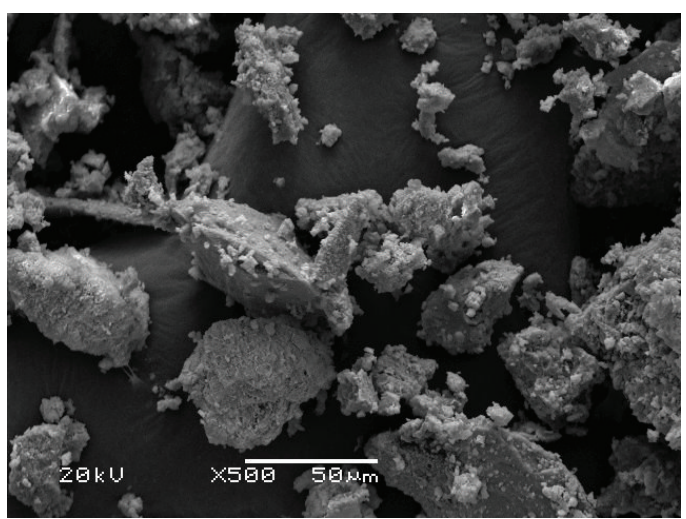

(a)

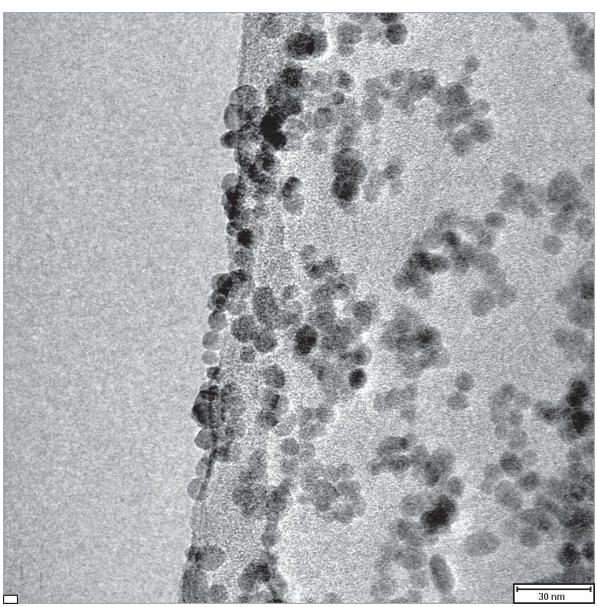

(c)

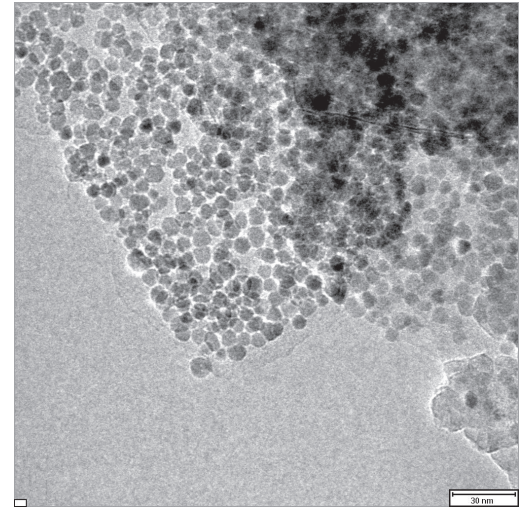

(b)

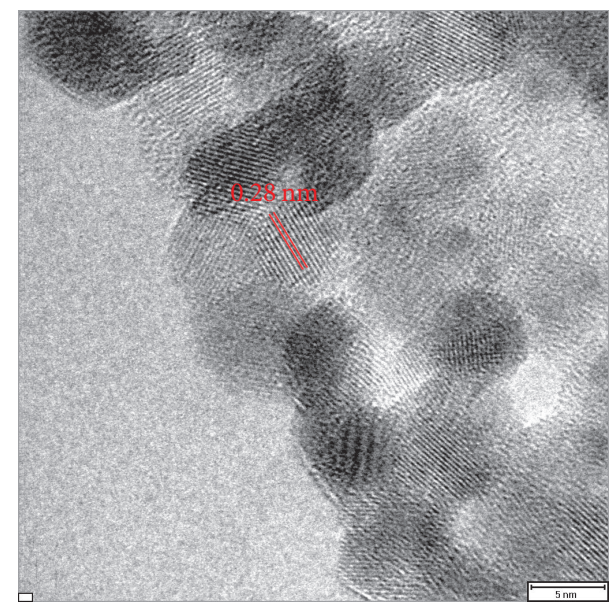

(d)

FIGURE 3: SEM and TEM of powders.

can be concluded that the X-ray diffraction patterns of nano$\mathrm{ZnO} /$ bentonite under calcination temperature of 100 and $200^{\circ} \mathrm{C}$ are not integrated because the peak of (002) crystal plane is not obvious. When the calcination temperature is above $300^{\circ} \mathrm{C}$, all the characteristic peaks are observed clearly with a high intensity. Nano- $\mathrm{ZnO}$ which is acquired under $200^{\circ} \mathrm{C}$ exhibits an amorphous structure and a wider half-peak width than that of 300 and $400^{\circ} \mathrm{C}$. According to Scherrer equation [19], the particle sizes of $\mathrm{ZnO}$ calcined at 200, 300, and $400^{\circ} \mathrm{C}$ are $5.7,6.8$, and $12.6 \mathrm{~nm}$.

3.2. SEM and TEM Analysis. Figure 3 shows the SEM and TEM of composite materials. From Figure 3(a), the SEM of nano-ZnO/bentonite ( $\mathrm{ZnO}$ content: $60 \%$ ) composite presents a feature of big particle size, which is goof for its separation and recycled from aqueous. From Figure 3(b), the TEM of pure nano-ZnO exhibits a uniform spherical particle. The particle size of nano- $\mathrm{ZnO}$ is about $5-7 \mathrm{~nm}$ which can be prepared by sol-gel technology. Figure 3(c) shows the TEM of nano-ZnO/bentonite composite. From Figure 3(c), it can be seen clearly that nano- $\mathrm{ZnO}$ adheres to the surface of bentonite and expresses good dispersion. It tends to decrease the dosage and improve utilization of the photocatalyst. Figure $3(\mathrm{~d})$ is HRTEM of nano- $\mathrm{ZnO} /$ bentonite. The particle size of nano- $\mathrm{ZnO}$ is from 5 to $10 \mathrm{~nm}$ which is similar to $\mathrm{XRD}$ results. The lattice spacing determined from HRTEM is $0.28 \mathrm{~nm}[20,21]$, which is consistent with (100) plane of $\mathrm{ZnO}$.

3.3. Effect of $\mathrm{ZnO}$ Content on Nano- $\mathrm{ZnO} /$ Bentonite. Figure 4 shows photocatalytic performances of nano- $\mathrm{ZnO} /$ bentonite composites in which nano- $\mathrm{ZnO}$ contents range from $10 \%$ to $70 \%$. With the rise of the nano- $\mathrm{ZnO}$ percentage in composite, C.I. Acid Red 35 removal increases rapidly. At $200 \mathrm{~min}$ irradiation, the removals are $14.2 \%, 22.4 \%, 30.7 \%, 37.9 \%, 79.6 \%$, and $84.9 \%$ with the corresponding $\mathrm{ZnO}$ contents of $10 \%$, $20 \%, 30 \%$, 40\%, 50\%, and $60 \%$, respectively. When the $\mathrm{ZnO}$ content continues to reach $70 \%$, the dye removal presents a descending tendency to $71.5 \%$ at $200 \mathrm{~min}$. According to many literatures about nanomaterial photocatalytic performance, the degradation process of organic contamination follows pseudo-first-order kinetics $[22,23]$. According to the integral type of the first-order kinetics $\left(\ln C_{0} / C_{t}=\right.$ $\left.k_{\mathrm{ap}} t\right)$, the apparent rate constant $\left(k_{\mathrm{ap}}\right)$ is the rate of slope in the linear relationship. From Figure 4, the decomposition processes of C.I. Acid Red 35 follow pseudo-first-order kinetics because $\ln \left(C_{0} / C_{t}\right)$ and irradiation time exhibit linear relationship at different photocatalysts. All the correlation coefficients $\left(R^{2}\right)$ are above 0.98 . The apparent rate constants 

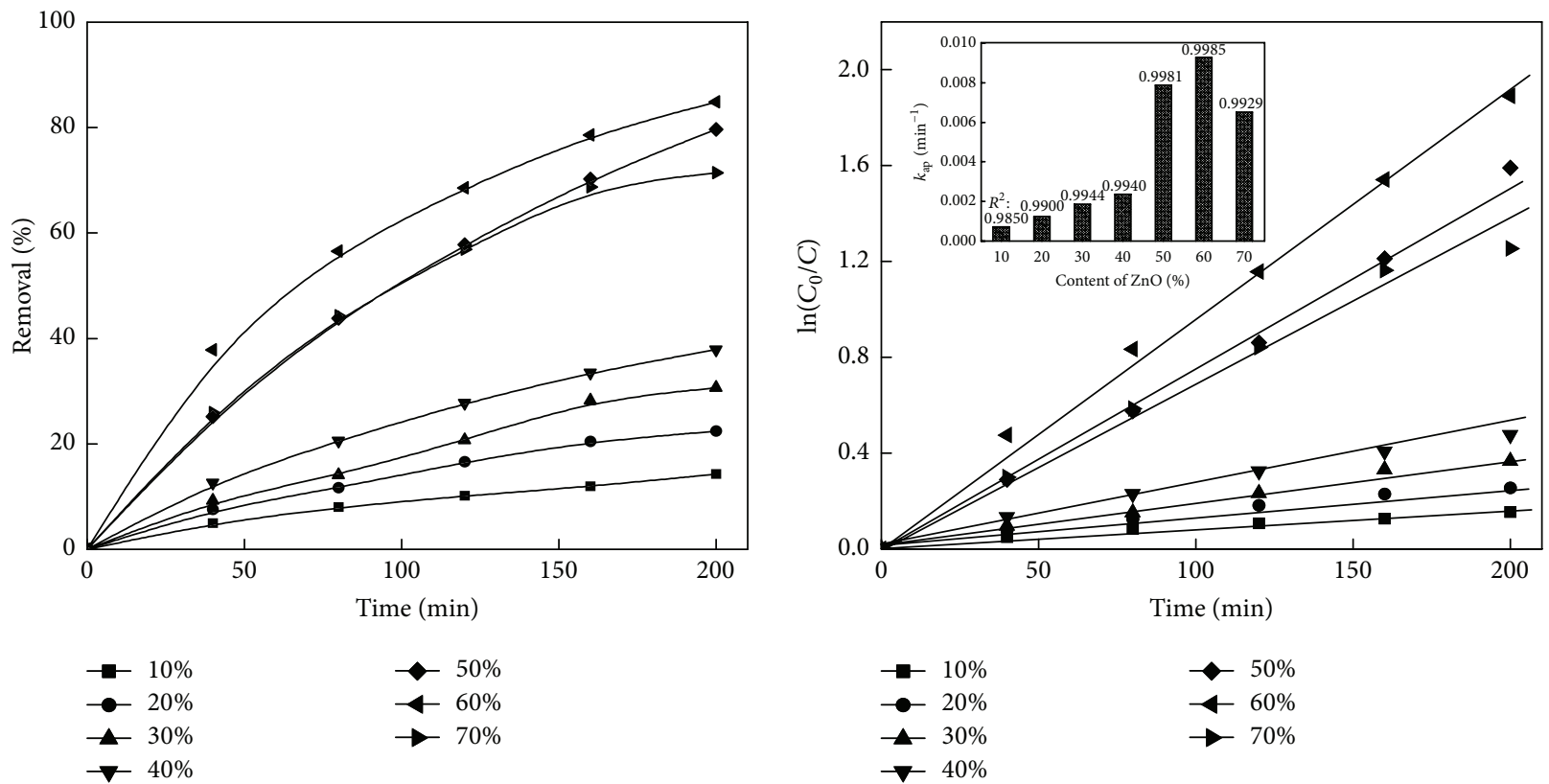

Figure 4: Effect of $\mathrm{ZnO}$ content on nano- $\mathrm{ZnO} /$ bentonite composite (catalyst dosage: $0.6 \mathrm{~g} \mathrm{~L}^{-1}$, C.I. Acid Red 35 initial dosage: $0.02 \mathrm{~g} \mathrm{~L}{ }^{-1}$, and calcination temperature $200^{\circ} \mathrm{C}$ ).

are $0.0007 \mathrm{~min}^{-1}, 0.0012 \mathrm{~min}^{-1}, 0.0018 \mathrm{~min}^{-1}, 0.0024 \mathrm{~min}^{-1}$, $0.0079 \mathrm{~min}^{-1}, 0.0093 \mathrm{~min}^{-1}$, and $0.0065 \mathrm{~min}^{-1}$ with the $\mathrm{ZnO}$ contents in the composites of $10 \%, 20 \%, 30 \%, 40 \%, 50 \%$, $60 \%$, and $70 \%$, respectively. Therefore, the best $\mathrm{ZnO}$ content in nano- $\mathrm{ZnO} /$ bentonite composite is $60 \%$ with $0.0093 \mathrm{~min}^{-1}$ apparent rate constant and $84.9 \%$ C.I. Acid Red 35 removal.

Under UV irradiation, electronic $\left(\mathrm{e}^{-}\right)$can be agitated from valence band (VB) to conduction band (CB) of $\mathrm{ZnO}$ to produce hole $\left(\mathrm{h}^{+}\right)$. The hole can react with hydroxyl ion to generate hydroxyl radical $\left({ }^{\circ} \mathrm{OH}\right)$. The ${ }^{\bullet} \mathrm{OH}$ shows a strong oxidation ability to decompose the organic contamination in aqueous $[7,10,23]$. The number of ${ }^{\circ} \mathrm{OH}$ can be increased with the rise of nano- $\mathrm{ZnO}$ content in nano- $\mathrm{ZnO} /$ bentonite. However, excessive $\mathrm{ZnO}$ in composite photocatalyst may aggregate together to increase nano- $\mathrm{ZnO}$ particle size. The big particle size of $\mathrm{ZnO}$ can reduce the quantum size effect and decrease the catalytic activity. On the other hand, bentonite has a good ability of adsorption of organic contaminants. The high $\mathrm{ZnO}$ content means the low bentonite in composite photocatalyst. The decline of adsorption ability of $\mathrm{ZnO} /$ bentonite also leads to the decrease of catalytic activity. So, the $60 \% \mathrm{ZnO}$ content in $\mathrm{ZnO}$ /bentonite composite is the optimal value in this study.

3.4. Effect of Calcination Temperature. The precursor obtained after sol-gel procedure was treated by calcination. The nano- $\mathrm{ZnO} /$ bentonite composites were prepared at different calcination temperatures of $200^{\circ} \mathrm{C}, 300^{\circ} \mathrm{C}, 400^{\circ} \mathrm{C}$, and $500^{\circ} \mathrm{C}$. The catalytic activity of nano- $\mathrm{ZnO} /$ bentonite composite is shown in Figure 5. From Figure 5, it is clearly seen that the precursor has a little photocatalytic activity. Under the calcination temperature of $200^{\circ} \mathrm{C}$, nano$\mathrm{ZnO} /$ bentonite has the best catalytic activity. When the calcination temperature is $300^{\circ} \mathrm{C}$, the catalytic efficiency has a little decrease. When the calcination temperature reaches $400^{\circ} \mathrm{C}$, the catalyst is in the inactivation state. After 200 min UV irradiation, the C.I. Acid Red 35 removals are $25.8 \%, 84.9 \%, 80.9 \%, 11.4 \%$, and $10.5 \%$ with the calcination temperatures at $100^{\circ} \mathrm{C}, 200^{\circ} \mathrm{C}, 300^{\circ} \mathrm{C}, 400^{\circ} \mathrm{C}$, and $500^{\circ} \mathrm{C}$, respectively. From Figure 5, the degradation processes of C.I. Acid Red 35 using these five nano- $\mathrm{ZnO} /$ bentonite composites follow first-order kinetics and the correlation coefficients $\left(R^{2}\right)$ are above 0.98 .

With the rise of calcination temperature, the particle size of nano- $\mathrm{ZnO}$ increases according to the XRD results. The glomeration phenomenon of $\mathrm{ZnO}$ is very serious and $\mathrm{ZnO}$ dispersion in composite is poor at a high calcination temperature. Quantum size effect especially has almost disappeared when the calcination temperature is above $400^{\circ} \mathrm{C}$. Therefore, the photocatalysts at $400^{\circ} \mathrm{C}$ and $500^{\circ} \mathrm{C}$ calcination temperature have a very poor activity. The best calcination temperature is $200^{\circ} \mathrm{C}$.

3.5. Effect of Nano-ZnO/Bentonite Concentration. A series of experiments were carried out by varying the dosages of nano$\mathrm{ZnO} /$ bentonite composite from 0.2 to $0.7 \mathrm{~g} \mathrm{~L}^{-1}$ in order to determine the effect of catalyst amounts. Color removal of C.I. Acid Red 35 is depicted at different photocatalyst addition in Figure 6. The degradation tendency of C.I. Acid Red 35 increases with the addition dosage of nano- $\mathrm{ZnO} /$ bentonite ranging from 0.2 to $0.6 \mathrm{~g} \mathrm{~L}^{-1}$. But color removal has a bit reduction when the dosage of composite catalyst improves to $0.7 \mathrm{~g} \mathrm{~L}^{-1}$. With $200 \mathrm{~min} \mathrm{UV}$ irradiation, the removals of C.I. Acid Red 35 are 45.3\%, 49.5\%, 73.1\%, 79.5\%, 84.9\%, and $67.1 \%$ as the catalyst dosages are $0.2 \mathrm{~g} \mathrm{~L}^{-1}, 0.3 \mathrm{~g} \mathrm{~L}^{-1}, 0.4 \mathrm{~g} \mathrm{~L}^{-1}$, $0.5 \mathrm{~g} \mathrm{~L}^{-1}, 0.6 \mathrm{~g} \mathrm{~L}^{-1}$, and $0.7 \mathrm{~g} \mathrm{~L}^{-1}$, respectively. From Figure 6, 

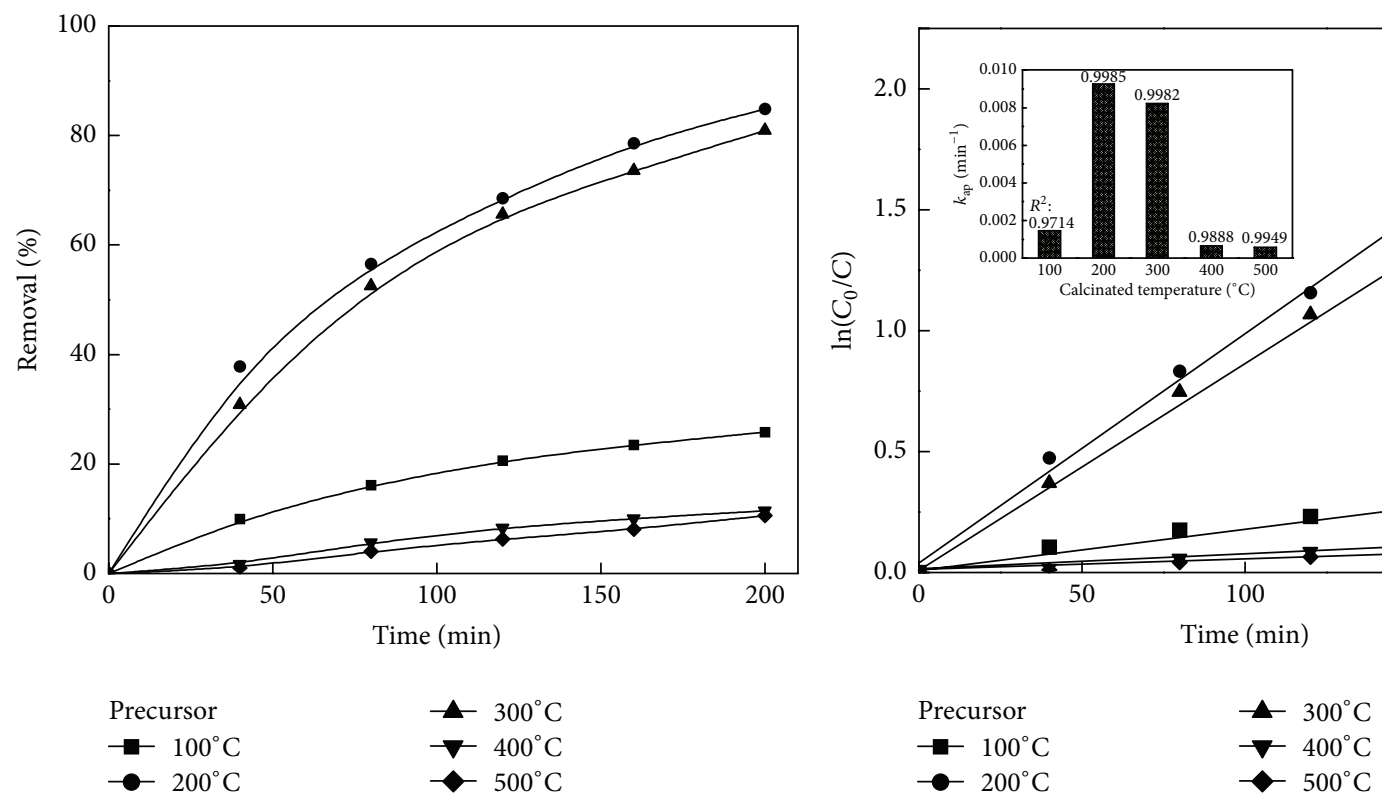

Figure 5: Effect of calcination temperature ( $\mathrm{ZnO}$ content: $60 \%$, C.I. Acid Red 35 initial dosage: $0.02 \mathrm{~g} \mathrm{~L}^{-1}$, and catalyst dosage: $0.6 \mathrm{~g} \mathrm{~L}{ }^{-1}$ ).
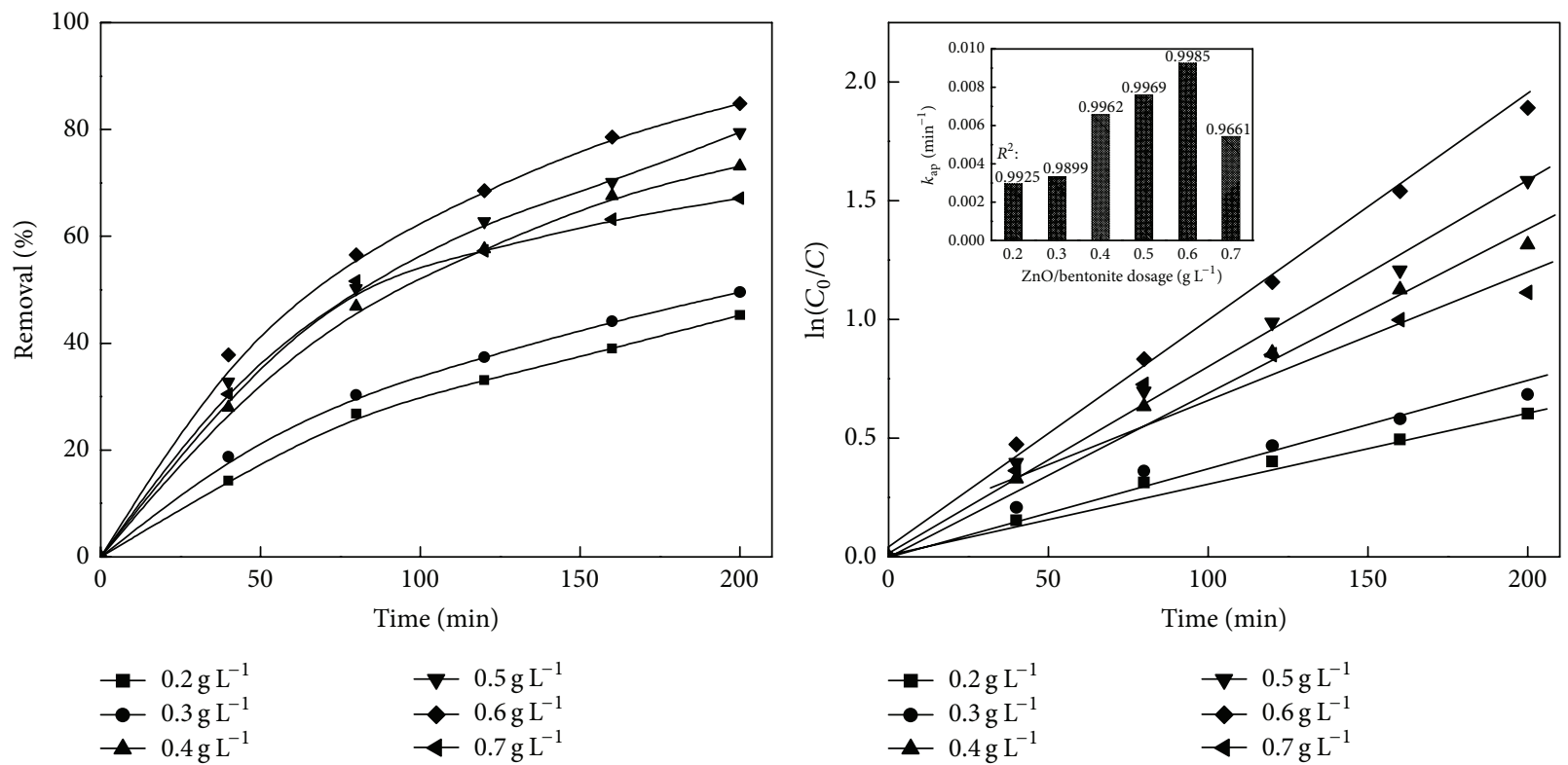

Figure 6: The effect of nano- $\mathrm{ZnO} /$ bentonite composite concentration ( $\mathrm{ZnO}$ content: $60 \%$, calcination temperature $200^{\circ} \mathrm{C}$, and C.I. Acid Red 35 initial dosage: $0.02 \mathrm{~g} \mathrm{~L}^{-1}$ ).

the degradation processes of C.I. Acid Red 35 follow pseudofirst-order kinetics when catalyst dosages range from 0.2 to $0.6 \mathrm{~g} \mathrm{~L}^{-1}$, as the correlation coefficients $\left(R^{2}\right)$ are above 0.98 . However, catalytic performance fails to follow pseudo-firstorder kinetics with only $0.96 R^{2}$ value when catalyst addition is $0.7 \mathrm{~g} \mathrm{~L}^{-1}$. The apparent rate constants are $0.00295 \mathrm{~min}^{-1}$, $0.00332 \mathrm{~min}^{-1}, 0.00657 \mathrm{~min}^{-1}, 0.0076 \mathrm{~min}^{-1}, 0.00927 \mathrm{~min}^{-1}$, and $0.00542 \mathrm{~min}^{-1}$ with the corresponding catalyst dosages of $0.2 \mathrm{gL}^{-1}, 0.3 \mathrm{gL}^{-1}, 0.4 \mathrm{gL}^{-1}, 0.5 \mathrm{gL}^{-1}, 0.6 \mathrm{gL}^{-1}$, and $0.7 \mathrm{gL}^{-1}$. Therefore, $0.6 \mathrm{~g} / \mathrm{L}$ is the optimum catalyst dosage.
The phenomenon reveals the fact that more available active sites on the catalyst surface can absorb photons from UV-lamp to promote the valence band electron to the conduction band to oxidize C.I. Acid Red 35. On the other hand, with higher loading levels, the nano- $\mathrm{ZnO} /$ bentonite composite powder may reflect, screen, and scatter the radiation from UV-lamp and reduce the photonic flux within the irradiated solution. Another reason is that the catalyst surface probably becomes unavailable for photoabsorption because of agglomeration and sedimentation of photocatalyst particles. 

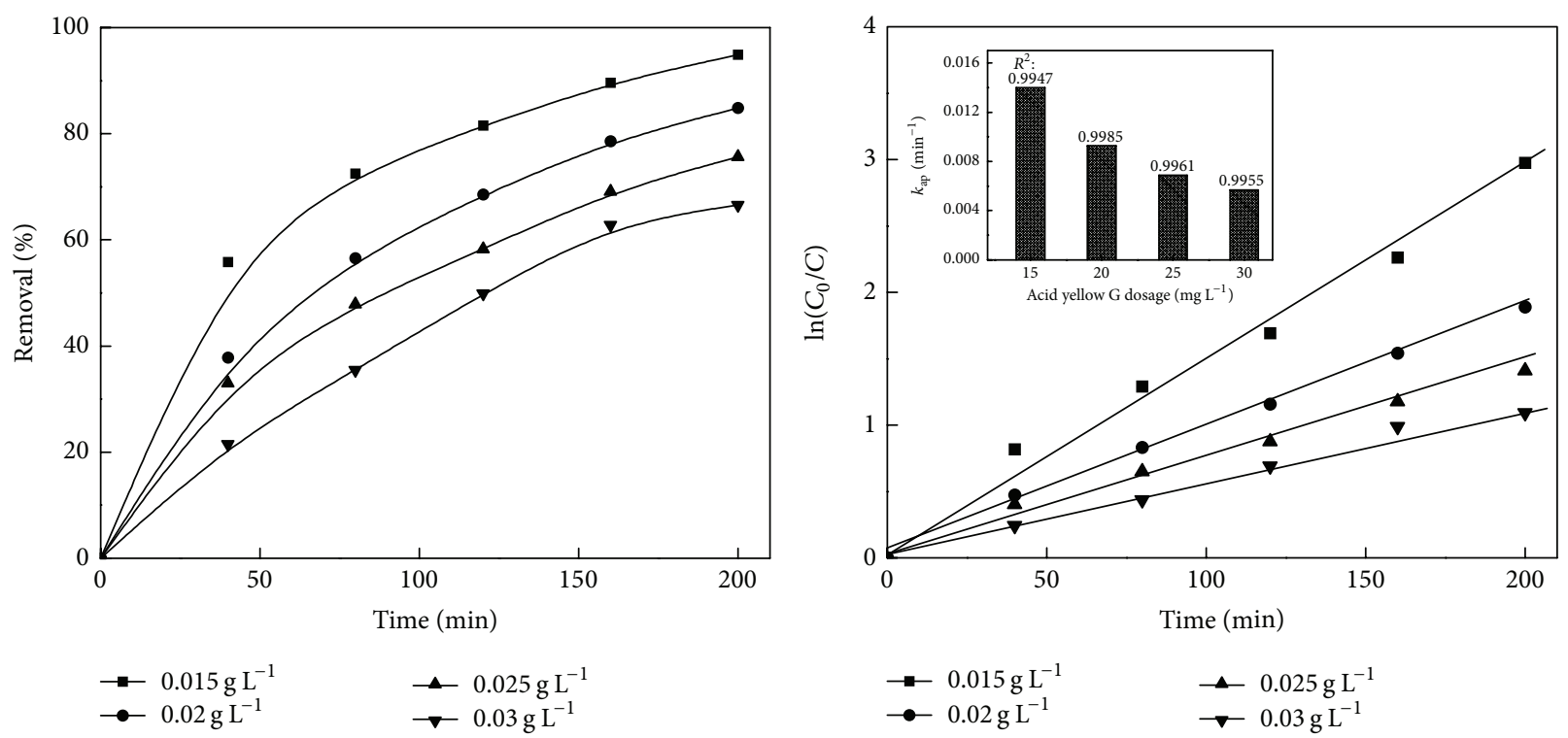

Figure 7: Effect of C.I. Acid Red 35 initial concentration ( $\mathrm{ZnO}$ content: $60 \%$, catalyst dosage: $0.6 \mathrm{~g} \mathrm{~L}^{-1}$, and calcination temperature $200^{\circ} \mathrm{C}$ ).

3.6. Effect of C.I. Acid Red 35 Initial Dosage. To study the influence of initial dye concentration on color removal, the initial C.I. Acid Red 35 concentrations ranging from 0.015 to $0.03 \mathrm{~g} \mathrm{~L}^{-1}$ are investigated in Figure 7. As can be seen from Figure 7, the removal of C.I. Acid Red 35 presents a decrease tendency with increasing of the initial C.I. Acid Red 35 concentration. For instance, the C.I. Acid Red 35 removal after $200 \mathrm{~min}$ is about $94.9 \%$ with initial dosage of $0.015 \mathrm{~g} \mathrm{~L}^{-1}$, but it decreases to $66.5 \%$ when it is $0.03 \mathrm{~g} \mathrm{~L}^{-1}$. The apparent constants have a great decrease from $0.014 \mathrm{~min}^{-1}$ to $0.057 \mathrm{~min}^{-1}$ with the rise of C.I. Acid Red 35 concentration from 0.015 to $0.03 \mathrm{~g} \mathrm{~L}^{-1}$. The correlation coefficients $\left(R^{2}\right)$ are above 0.99 when C.I. Acid Red 35 concentration varies from 0.015 to $0.03 \mathrm{~g} \mathrm{~L}^{-1}$. Although the rise of dye concentration in aqueous solution increases the number of dye molecules, the hydroxyl radical has no change. Therefore, the color removal and the decolorizing rate constant decrease as the initial concentration of C.I. Acid Red 35 increases.

\section{Conclusions}

Nano-ZnO supported on bentonite was prepared to form composite photocatalyst by sol-gel method. According to the $\mathrm{XRD}$ and TEM analysis, $5.7 \mathrm{~nm} \mathrm{ZnO}$ in nano- $\mathrm{ZnO} /$ bentonite was acquired at $200^{\circ} \mathrm{C}$ calcination temperature. The removal of C.I. Acid Red 35 could reach $84.9 \%$ with optimum $\mathrm{ZnO} /$ bentonite dosage of $0.6 \mathrm{~g} \mathrm{~L}^{-1}$ after $200 \mathrm{~min}$ reaction. The $60 \% \mathrm{ZnO}$ content in $\mathrm{ZnO} /$ bentonite composite exhibited a great photocatalytic activity to treat C.I. Acid Red 35. The photocatalytic process followed pseudo-first-order kinetics and the best apparent rate constant was $0.00927 \mathrm{~min}^{-1}$ with correlation coefficient $\left(R^{2}\right)$ of above 0.98 .

\section{Conflict of Interests}

The authors declare that there is no conflict of interests regarding the publication of this paper.

\section{Acknowledgments}

This work is supported by the National Natural Science Foundation of China (no. 21006057) and Henan Provincial Science and Technology Foundation (nos. 142102210427 and 142300410202).

\section{References}

[1] T. Li, L. Zhao, Y. He, J. Cai, M. Luo, and J. Lin, "Synthesis of g- $\mathrm{C}_{3} \mathrm{~N}_{4} / \mathrm{SmVO}_{4}$ composite photocatalyst with improved visible light photocatalytic activities in RhB degradation," Applied Catalysis B: Environmental, vol. 129, no. 17, pp. 255-263, 2013.

[2] D. Pugliese, A. Lamberti, F. Bella, A. Sacco, S. Bianco, and E. Tresso, " $\mathrm{TiO}_{2}$ nanotubes as flexible photoanode for backilluminated dye-sensitized solar cells with hemi-squaraine organic dye and iodine-free transparent electrolyte," Organic Electronics: Physics, Materials, Applications, vol. 15, no. 12, pp. 3715-3722, 2014

[3] R. Djellabi, M. F. Ghorab, G. Cerrato et al., "Photoactive $\mathrm{TiO}_{2}$-montmorillonite composite for degradation of organic dyes in water," Journal of Photochemistry and Photobiology A: Chemistry, vol. 295, pp. 57-63, 2014.

[4] L. V. Trandafilović, R. K. Whiffen, S. Dimitrijević-Branković, M. Stoiljković, A. S. Luyt, and V. Djoković, " $\mathrm{ZnO} / \mathrm{Ag}$ hybrid nanocubes in alginate biopolymer: synthesis and properties," Chemical Engineering Journal, vol. 253, no. 1, pp. 341-349, 2014.

[5] Q. I. Rahman, M. Ahmad, S. K. Misra, and M. Lohani, "Effective photocatalytic degradation of rhodamine $\mathrm{B}$ dye by $\mathrm{ZnO}$ 
nanoparticles," Materials Letters, vol. 91, no. 15, pp. 170-174, 2013.

[6] W. He, H. Zhao, H. Jia, J.-J. Yin, and Z. Zheng, "Determination of reactive oxygen species from $\mathrm{ZnO}$ micro-nano structures with shape-dependent photocatalytic activity," Materials Research Bulletin, vol. 53, no. 3, pp. 246-250, 2014.

[7] R. Khan, M. S. Hassan, L.-W. Jang et al., "Low-temperature synthesis of $\mathrm{ZnO}$ quantum dots for photocatalytic degradation of methyl orange dye under UV irradiation," Ceramics International, vol. 40, no. 9, pp. 14827-14831, 2014.

[8] S. Ameen, M. S. Akhtar, M. Nazim, and H.-S. Shin, "Rapid photocatalytic degradation of crystal violet dye over $\mathrm{ZnO}$ flower nanomaterials," Materials Letters, vol. 96, pp. 228-232, 2013.

[9] S. Su, S. X. Lu, and W. G. Xu, "Photocatalytic degradation of reactive brilliant blue $\mathrm{X}-\mathrm{BR}$ in aqueous solution using quantumsized ZnO," Materials Research Bulletin, vol. 43, no. 8-9, pp. 2172-2178, 2008.

[10] S. C. Motshekga, S. S. Ray, M. S. Onyango, and M. N. B. Momba, "Microwave-assisted synthesis, characterization and antibacterial activity of $\mathrm{Ag} / \mathrm{ZnO}$ nanoparticles supported bentonite clay," Journal of Hazardous Materials, vol. 262, no. 15, pp. 439-446, 2013.

[11] V.-A. Antohe, M. Mickan, F. Henry, R. Delamare, L. Gence, and L. Piraux, "Self-seeded electrochemical growth of $\mathrm{ZnO}$ nanorods using textured glass/Al-doped $\mathrm{ZnO}$ substrates," Applied Surface Science, vol. 313, no. 15, pp. 607-614, 2014.

[12] M. Seo, Y. Jung, D. Lim, D. Cho, and Y. Jeong, "Piezoelectric and field emitted properties of controlled $\mathrm{ZnO}$ nanorods on CNT yarns," Materials Letters, vol. 92, no. 1, pp. 177-180, 2013.

[13] S. Meshram, R. Limaye, S. Ghodke, S. Nigam, S. Sonawane, and R. Chikate, "Continuous flow photocatalytic reactor using ZnO-bentonite nanocomposite for degradation of phenol," Chemical Engineering Journal, vol. 172, no. 2-3, pp. 1008-1015, 2011.

[14] N.-O. Saelim, R. Magaraphan, and T. Sreethawong, "Preparation of sol-gel $\mathrm{TiO}_{2} /$ purified Na-bentonite composites and their photovoltaic application for natural dye-sensitized solar cells," Energy Conversion and Management, vol. 52, no. 8-9, pp. 28152818, 2011.

[15] N. Hamzah, N. M. Nordin, A. H. A. Nadzri, Y. A. Nik, M. B. Kassim, and M. A. Yarmo, "Enhanced activity of $\mathrm{Ru} / \mathrm{TiO}_{2}$ catalyst using bisupport, bentonite- $\mathrm{TiO}_{2}$ for hydrogenolysis of glycerol in aqueous media," Applied Catalysis A: General, vol. 419, no. 1, pp. 133-141, 2012.

[16] J. Li, Suyoulema, W. Wang, and Sarina, "A study of photodegradation of sulforhodamine $\mathrm{B}$ on $\mathrm{Au}-\mathrm{TiO}_{2}$ /bentonite under UV and visible light irradiation," Solid State Sciences, vol. 11, no. 12, pp. 2037-2043, 2009.

[17] H. Xu, T. Yu, and J. Liu, "Photo-degradation of Acid Yellow 11 in aqueous on nano- $\mathrm{ZnO} /$ Bentonite under ultraviolet and visible light irradiation," Materials Letters, vol. 117, no. 15, pp. 263-265, 2014.

[18] H. S. Hafez, "Highly active $\mathrm{ZnO}$ rod-like nanomaterials: synthesis, characterization and photocatalytic activity for dye removal," Physica E: Low-Dimensional Systems and Nanostructures, vol. 44, no. 7-8, pp. 1522-1527, 2012.

[19] M. M. Ba-Abbad, A. A. H. Kadhum, A. B. Mohamad, M. S. Takriff, and K. Sopian, "Visible light photocatalytic activity of $\mathrm{Fe}^{3+}$-doped $\mathrm{ZnO}$ nanoparticle prepared via sol-gel technique," Chemosphere, vol. 91, no. 11, pp. 1604-1611, 2013.

[20] Y. Lou, S. Yuan, Y. Zhao et al., "A simple route for decorating $\mathrm{TiO}_{2}$ nanoparticle over $\mathrm{ZnO}$ aggregates dye-sensitized solar cell," Chemical Engineering Journal, vol. 229, no. 1, pp. 190-196, 2013.

[21] C. Li, R. Hu, L. Qin, R. Ding, X. Li, and H. Wu, "Enhanced photocatalytic activity of $\mathrm{ZnO} / \mathrm{La}_{2} \mathrm{O}_{3}$ composite modified by potassium for phenol degradation," Materials Letters, vol. 113, no. 15, pp. 190-194, 2013.

[22] W. G. Xu, S. F. Liu, S. X. Lu, S. Y. Kang, Y. Zhou, and H. F. Zhang, "Photocatalytic degradation in aqueous solution using quantum-sized $\mathrm{ZnO}$ particles supported on sepiolite," Journal of Colloid and Interface Science, vol. 351, no. 1, pp. 210-216, 2010.

[23] H. Cao, X. Lin, H. Zhan, H. Zhang, and J. Lin, "Photocatalytic degradation kinetics and mechanism of phenobarbital in $\mathrm{TiO}_{2}$ aqueous solution," Chemosphere, vol. 90, no. 4, pp. 1514-1519, 2013. 

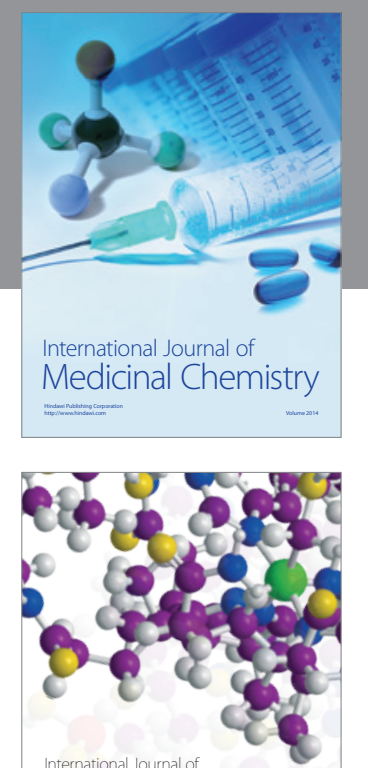

\section{Carbohydrate} Chemistry

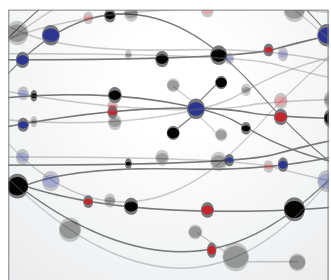

The Scientific World Journal
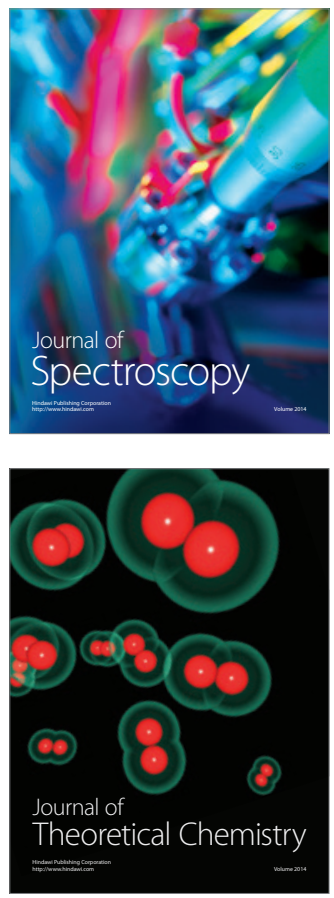
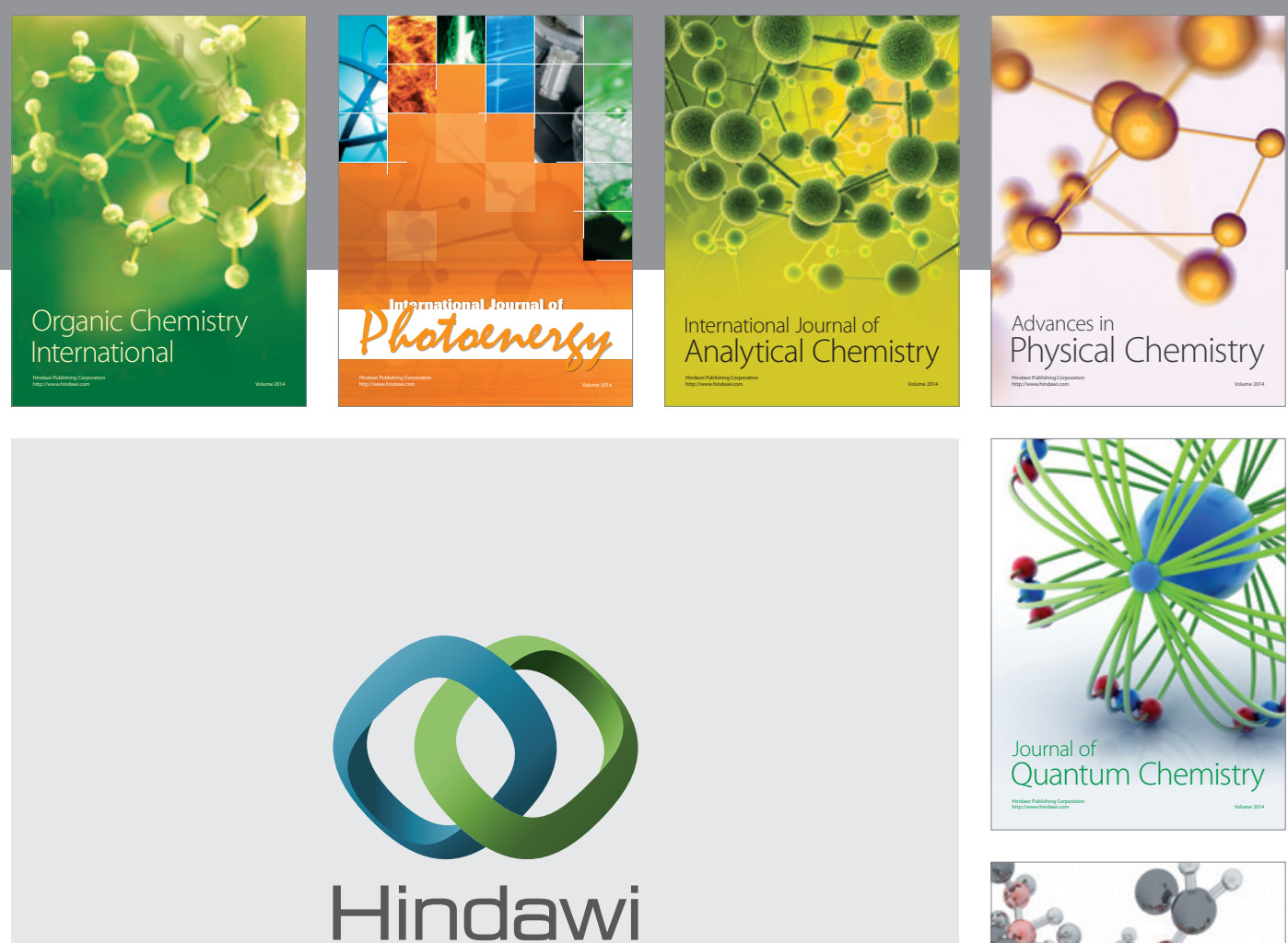

Submit your manuscripts at

http://www.hindawi.com

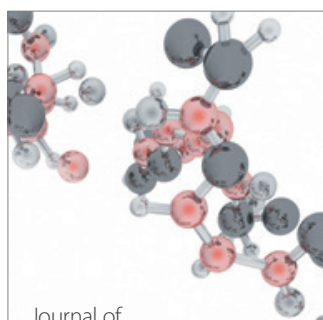

Analytical Methods

in Chemistry

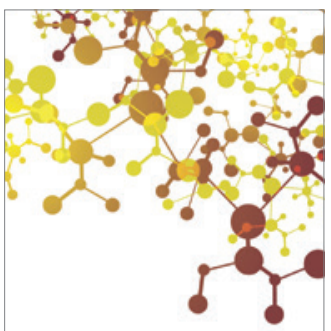

Journal of

Applied Chemistry

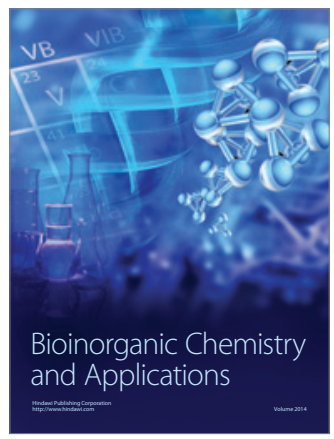

Inorganic Chemistry
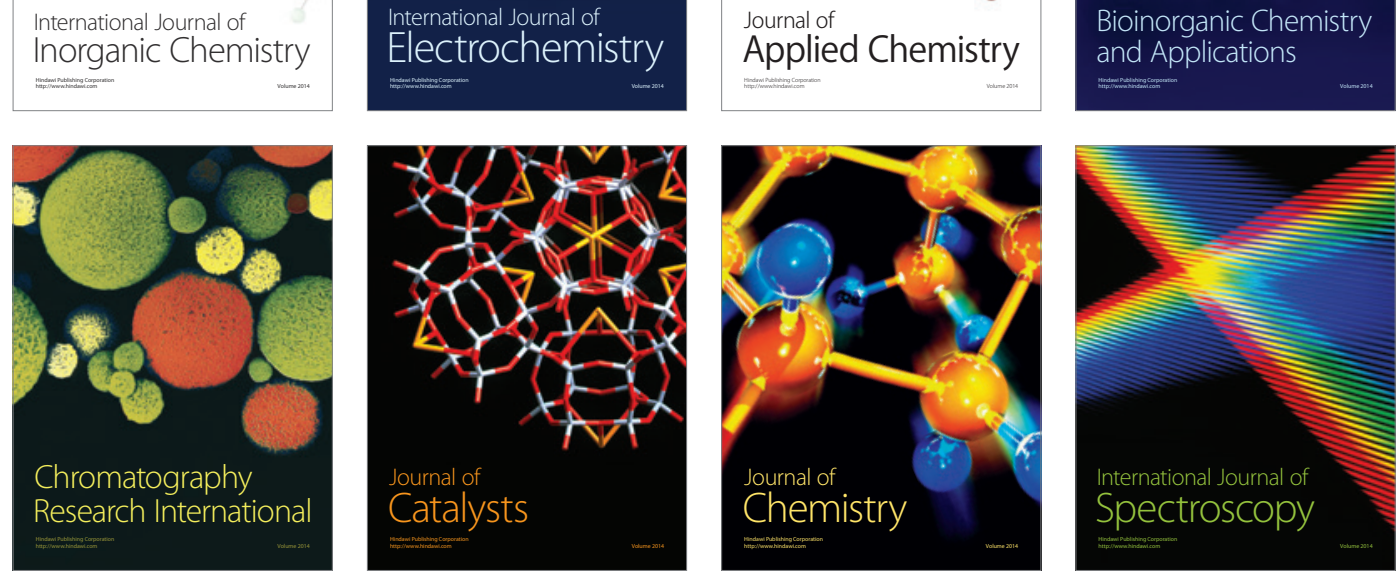